\title{
Sharpening Competitive Edge through Procurement Innovation: Perspectives from Chinese International Construction Companies
}

Weisheng Lu' ${ }^{1}$ Anita M. M. Liu²; Steve Rowlinson ${ }^{3}$; and S. W. Poon ${ }^{4}$

${ }^{1}$ Assistant Professor, Dept. of Real Estate and Construction, Faculty of Architecture, Univ. of Hong Kong, Pokfulam, Hong Kong (corresponding author). E-mail: wilsonlu@hku.hk

${ }^{2}$ Professor, Dept. of Real Estate and Construction, Faculty of Architecture, Univ. of Hong Kong, Pokfulam, Hong Kong.

${ }^{3}$ Professor, Dept. of Real Estate and Construction, Faculty of Architecture, Univ. of Hong Kong, Pokfulam, Hong Kong.

${ }^{4}$ Associate Professor, Dept. of Real Estate and Construction, Faculty of Architecture, Univ. of Hong Kong, Pokfulam, Hong Kong.

\section{Abstract}

The international construction business is witnessing a trend towards the delivery of projects through the adoption of innovative procurement systems, which allow companies to gain competitive advantages and to potentially deliver enhanced value to society. Notably, Chinese companies are making steady inroads into the international construction market by enhancing competitiveness. However, we know little about the extent to which Chinese international construction companies (CICCs) perceive procurement innovation and how this factor may relate to their recent success. This research aims to fill the void based on interviews with nine CICC key decision-makers and experts in this area, and the capturing of their perspectives. It is found that CICCs are gradually adopting procurement innovation as a competitive strategy. Although procurement innovation is conducive to competitive advantage in the long run, CICCs have to pay tuition fee when they first enter the market. Thus a "wait-and-see" attitude exists in respect of a long term vision. Unlike the traditional win-lose competitive bidding system, competing through 
procurement innovation can lead to larger, more suitable market presence. By succinctly describing the CICC story in the international market this research not only provides CICCs themselves with insights into current procurement innovations existing within the construction sector, but also enables other companies to understand the nature of CICCs with which they might compete or collaborate in the near future.

Keywords: Procurement innovation, international construction, competitiveness, construction companies, China

\section{Introduction}

Globalization of the world economy means that much of today's construction exists in an internationally interdependent marketplace. Statistics published by the Engineering News-Record (ENR, 2010), for example, show that the ENR's top 225 international contractors (TIC 225) generated $\$ 383.78$ billion in revenue from projects outside their home countries in 2009, up $0.4 \%$ from $\$ 382.44$ billion in 2008. Advanced technology, fast transportation, convenient communications, effective knowledge transfer, integrated markets, and trade liberalization have all helped transcend traditional country boundaries and transform the international construction market into a fiercely competitive place.

Under this circumstance, a main company strategy is to sustain their competitiveness through continuous innovation of procurement systems. Innovative procurement systems such as Build Operate Transfer (BOT), Private Finance Initiative (PFI), Public Private Partnering (PPP), and prime contracting have been adopted in the procurement of a number of significant projects that would not have been possible using traditional 
approaches (e.g. MacDonald, 2002). These innovations have created new business opportunities for companies.

Notably, Chinese international construction companies (CICCs) are making impressive progress in this marketplace. 54 CICCs were listed on the ENR's Top 225 International Contractors (TIC225) in 2010, and in 2009 alone, gained a total contracting revenue of $\$ 50.57$ billion from their overseas construction market (ENR, 2010). Lu et al. (2009) reported that CICCs' business in the international market presents the following new patterns: (1) CICCs are able to compete in more sophisticated markets such as the US and Europe although about 70\% of total turnover still derives from Asia and Africa; (2) the projects types that CICCs are able to compete for are of increasing diversity, including water, power, petroleum, and the undertaking of financing, construction and operation in service activities. It seems that CICCs have sharpened their competitive edge by catching up in the procurement innovation field. However, little is known on how CICCs actually view the role of procurement innovation and how and whether it has been deliberately used as a competitive strategy sustaining their recent success.

The aim of this research is to ascertain how CICCs perceive procurement innovation with a view to how it can be used to improve their international competitiveness. The paper is structured into four sections. Firstly, a literature review is presented concentrating on understanding the key concepts of procurement, innovation, and procurement innovation. Research questions are raised based on the literature review. Secondly, the research 
design and research methods adopted by the authors are described. In the third section, research findings are presented, and finally, key conclusions are drawn.

\section{Procurement and procurement innovation in the construction industry}

Recent years have seen a burgeoning of research into the field of construction procurement. However, the concept of procurement is not an easy one to comprehend. Largely based on the evolution of the concept contributed by various writers (e.g. Franks and Harlow, 1990; Turner, 1990; Masterman, 1992; McDermott et al., 1994; Rowlinson and McDermott, 1999; Walker and Hampson, 2002; Hughes et al., 2006; Walker and Rowlinson, 2008).

Whilst the understanding of procurement now covers broader issues, it is still often understood as obtaining or purchasing resources such as materials, labor, and machinery needed to realize a construction project. This resonates with Kumaraswamy and Dissanayaka (1998) who see "procurement" as "the action of process of acquiring or obtaining material, property or services at the operational level”; "building procurement" as "the amalgam of activities undertaken by a client to obtain a building"; and “construction procurement" as "the framework within which construction is brought about, acquired or obtained” in a less confrontational manner.

Procurement innovation can be understood differently by placing different emphasis on "procurement" and "innovation” aspects of the phrase. The concept has been seen as a driver of innovation, in respect of business competitiveness, improvements, and ultimately, economic growth. For example, a CBI/QinetiQ Innovation (2006) reported 
that public procurement spending in the UK stands at around $£ 150$ bn a year. The potential for using such spending to stimulate innovation in the UK was recognized in the DTI’s 2003 innovation report.

Alternatively, the concept can be understood as innovative procurement in contrast to those "traditional (conventional)" procurement methods in construction. Nonetheless, it is difficult to delineate a clear boundary between the "traditional" and "innovative" procurement methods. For example, writers generally agree that traditional procurement approach relates to discrete project phases including design development, tender, contract development, to construction delivery (Walker and Hampson, 2003:13; Walker and Rowlinson, 2007:45). The Design and building (D\&B) mode and its variants which emerged later are supposed to be innovative as they were new to the industry at that time. Raisbeck et al. (2010) defined 'traditional procurement' to include all non-PPP procurement approaches, including D\&B and 'alliances’.

According to the OECD and Statistical Office of the European Communities (1997), to innovate is the introduction of technologically new products or processes that are new to the organization. Innovation is also defined as an idea, practice, or object that is perceived as new by an individual or other unit of adoption (Rogers, 1995). If we take these definitions, any idea, practice, or object can be innovative as far as it is perceived as new by its adopter. Innovative procurement means different things to different adopters. Based on the above discussions, a working definition of procurement innovation is briefly defined as 
new methods to acquire project resources such as finance, technical skills, materials, labours, and professional services for the realization of a constructed facility.

Adoption of innovative procurement is increasingly the trend for some companies, in facing the challenges, realising more projects, and gaining competitiveness. The question addressed in this study was how procurement innovations were perceived by Chinese international construction companies (CICCs).

\section{Research design and methods}

To make sense of the perspectives of a CICC towards procurement innovation, a bunch of questions were posed as follows:

(1) What procurement innovations are actually adopted by CICCs?

(2) To which extent can it be said that the recent success of CICCs has benefited from procurement innovations?

(3) By considering the strengths, weaknesses, opportunities, threats, what should CICCs do to achieve even greater degree of international success through procurement innovation?

These broad questions, based on authors' experience and the above literature review, were designed in a way that allowed for some general "chat" with CICCs at the beginning and for more specific viewpoints thereafter. Given that procurement innovation is a broad topic and that CICCs all differ considerably in detail, it is extremely difficult, if not completely impossible, to enumerate in advance all questions that would 
address every subject area of interest. The questions are designed, therefore, to capture meaningful, yet not necessarily to exhaust all possible CICCs "perspectives" .

The authors came to a consensus that interview based qualitative research would be the most effective way of understanding CICC perspectives on the subject of procurement innovations. Interviews also allow for in-depth interpretation of the topic. To make sure that insightful perspectives would be captured, it was necessary that the interviewees should be at executive level or above and that they should have acquired plenty of experience in international construction. This further limited the number of interviewees but thanks to strong personal contacts, nine interviews were conducted.

Before the interviews, the questions were sent in advance for preview, and a suitable date then agreed. The interviews generally started with an explanation of the concept of procurement innovation. This was followed by the interviewees explaining the work and structure of their organizations. The research questions listed above were asked one by one. Each interview lasted 40-60 minutes. Not all nine interviews were recorded on audio tape but notes were taken in a way that key messages given out by interviewees would not be lost to subsequent analysis. The notes were suitably transcribed to allow for this and good attention was paid to language usage to ensure no information would be lost in translation.

\section{Analyses, discussions, and findings}

Global configuration of resources 
Along with globalization of the world economy, the ability to procure and align resources globally has become part of the natural competitive strategies of international contractors, including those from China. Here resources refer to materials, labours, technical expertise, professional services, management skills, finance, and so on. Given the cost formula in construction that the direct costs such as materials and labor account for up to $70 \%$ of overall construction cost (Patrascu, 1988), it is easy to understand the strategic imperative of procuring low-priced resources around the globe. Moreover, the procuring of resources globally can help shorten the logistic and supply chain. This is particularly useful for managing the prolonged supply chains of international construction projects, where resources required are not necessarily obtained from the home or host country.

Without specifically referring to the case of CICCs, interviewees did recommend some innovative procurement practices. In relation to the working of competition mechanism:

I will refer to an international construction company (hide its name here). It has three procurement offices, one in South America, one in Asia, and one in Europe. When there is a purchasing, the three offices will bid for it. For example, Asia office provides the market information in Asia, European office in Europe, and South American office looks after South America. I think that is very clever to create an internal competition.

Cross-sectoral learning is encouraged:

The car industry is doing very well in this procurement strategy. They manage their supply chain very well. They come to suppliers' factories, investigate their product line, train up their suppliers, and certify them. They maintain a stable supply chain and they often got what they want. Another example is supermarket guys. They are excellent in procurement. 
This reflects the fact that project managers worry about a reliable supply chain in undertaking construction. The construction industry, owing to the low entry barrier and the large number of small companies, is often criticized for its fragmentation and low-trust culture. In the car or aerospace industries, there are often dominant companies which make possible the above mentioned investigation, training, and certification.

As to the extent to which CICCs acquire resources globally, one of our interviewees, an English CEO who has competed and collaborated with CICCs for many years, reflected:

No, they are still doing mainly in China. They have a very strong network in China, knowing how to procure technical skills, materials, machineries in China. They have a good knowledge-base in China. That is their unique competitive advantage.

This resonates with Lu et al. (2009) which found that it is hardly a secret that low cost or good value for money sharpens the competitive edge of the CICCs. China's relatively comprehensive material and production systems make it possible to procure all the materials needed. The attractiveness of China's material market also lies in its low prices, although quality levels are highly controversial. To benefit from these advantages, international construction companies have established purchasing offices in China. For example, Hochtief has been developing a worldwide logistics operation in China to procure resources and has a joint venture with a materials testing company (ENR, 2008).

As to the experience of globe procurement, the interviewee suggested that information is the most important success factor. 
Chinese companies need a good information system to achieve excellence in procurement. Procurement information will be input to the system. The system can generate report automatically comparing price information etc. from multiple projects. That helped me a lot. Project managers don't like it. They prefer traditional way. Back to the perspectives for Chinese International Construction Companies, I don't think they have a good information system. The accuracy of procurement information largely relies on integrity of their project managers.

Whilst not fully agreed with the above comments, CICC interviewees also confirmed the importance of market information in global procurement:

We purchase bulk commodities in host country, machinery in China, while keeping a close eye on market prices in Europe and North America. Price is not the only factor taken into consideration; we will also assess the guarantee of delivery. Information is valuable for procurement innovation. Globalization of the economy and advancements in the information communication technology present both challenges and opportunities.

Another important project resource is labor. According to the English interviewee, labour is one of the strongest sources of CICC competitiveness:

Their main strengths are that (1) they can find low cost labor; and (2) labors tolerate adverse working conditions.

The two points echo with Lu et al (2009) who discovered that a major factor contributing to CICC rapid international expansion is an abundant supply of cheap yet skilled manpower, who often take it for granted that construction takes place normally in adverse environments and that working overtime is common. It can thus be observed that CICCs possess competitive advantages in markets where they can bring in their own labors and skilled workers (e.g. Africa, Singapore, and the Middle East). However, this advantage is 
eroding because of increasing salary, work permit issues, and the pressure applied to provide employment for host country personnel. As is already the case for their overseas competitor peers, CICCs increasingly perceive the procuring of labor as a new challenge ahead.

Innovative procurement systems in China's indigenous construction market

Analyses of CICC perspectives towards innovative procurement systems began within China's indigenous construction market for two reasons. First, most CICCs have both domestic and overseas businesses, which are mutually dependent by nature. The domestic market can provide a business buffer particularly when international construction is in recession. Second, according to Porter (1990), a sophisticated domestic market is an important element backing up international competitiveness. It is thus legitimate to investigate innovative procurement systems existing in China, and to examine how they foster CICC competitiveness in the international market, which is bound to be different from the Chinese market in many ways.

First of all, interviewees pointed out that the main procurement mode in China is still the traditional DBB (Design-Bid-Build), although even this was first introduced as an innovation in 1984 when competitive bidding and tendering were not then usual. Our interviewee reflected that:

Over the past decades, we have made significant improvement in engineering, technical skills, and construction methods. We are doing fine in project management. These are all achieved within China's market conditions; the whole China is a massive construction site. The increasingly sophisticated 
market helps achieve the above improvement. But we have not really made major breakthrough in procurement innovations. China is a big government, and a big client. (The interviewee may imply this has constrained procurement innovation in China).

More specifically, the academic interviewee pointed out that the current legal and regulation system is only conducive to traditional procurement modes:

For example, before any soil can be excavated, you have to get approval of the drawings. You can start next step only after the previous step has been approved (by government administrative departments).

However, he continued to argue:

Procurement innovation is something continuously happening in China, which has been an active part of the international construction market, even before its entry to WTO. Overseas companies entered China, bringing their innovative procurement methods such as EPC and BOT. Chinese companies are learning. For example, EPC is promoted by the government. BOT projects are widely reported, although without a special regulation on it. China's business environment is changing rapidly, which presents many challenges and opportunities for procurement innovation.

Another interviewee suggested that innovative procurement systems can be derived from traditional systems, or they can be created by adjusting existing systems, or both. Attentions should be paid to the past situations from which they were generated, and their suitability to the new environment.

Lu et al. (2011) revealed that in China an Agent-Construction System is now widely introduced for procuring non-profit-making public projects, i.e. urban roads, schools, hospitals, government offices, Olympic Games stadiums. Traditional procurement approaches still prevail in profit-making utilities, i.e. water, gas, telecom, sewage 
facilities, tolling roads, bridges and tunnels. PPP and its instances such as BOT and PFI have not proved to be as popular as expected. The English CEO, by emphasising that his company still the traditional contracting type, commented that:

The promotion of PFI in UK has its particular background. They need the participation from private sector. The situation is different here in Hong Kong or Mainland China. The Hong Kong government got the money. It is also about local politics which I haven't fully captured. As long as all these factors are existing, PFI wouldn't happen widely here in Hong Kong or in Mainland China.

Analysis of the interviews reveals that CICCs have relatively abundant amounts of finance in hand, as a result of fast development over the past years. Construction, if conducted using traditional modes, is not an extremely capital-intensive business. In addition, many companies, in particular SOEs, have raised funds by listing themselves on the stock markets in Mainland China or Hong Kong over the past few years. Although it is not certain whether their finances are as strong as those institutional investors, they can be treated as a new force in terms of the financing of international projects. Moreover, CICCs have developed such delivery capabilities as engineering expertise, technical skills, resource channels, and project management capacity. A “can-do" culture is highly respected amongst construction companies. CICCs can be seen as a new delivery force in the international construction market.

Innovative procurement systems in the international construction market

It is generally observed that there are two trends in innovative procurement approaches in the international construction market. Firstly, public procurement is shifting from 
traditional state-led approaches to partnering between public and private sectors (Godfrey, 1996; Egan, 1998; Winch, 2000). Secondly, integrated approaches are adopted to reduce the fragmentation and discontinuity by which the construction sector has long been plagued (Egan, 1998). Procurement innovations, however, present new challenges to the traditional individual financing, architecture, engineering, construction, and operation components of a project, requiring the integration of the processes as a whole.

Many CICCs are not acclimatized to the new challenges. Project financing is still a new area for Chinese companies. An interviewee reflected that:

We dare not set our foot in BOT, either in domestic or international market. We prefer investing in less risky areas, for example, we do have investment in cotton mills.

It is not new knowledge to CICCs that design, including architecture and engineering, is not only a high value-added profit center in its own right, but also has a knock-on effect on subsequent businesses such as construction, and export of materials and machinery. This is particularly true when international clients are increasingly adopting integrated approaches (e.g. D\&B) in procuring facilities. A big gap, however, has been observed between design and construction in CICCs due to historical reasons resulting from the old centrally planned economic system, and the fact that design institutes and construction companies have developed as separate profit centers. The interviewees reported that their in-house design capability is fairly weak, in comparison with that of the design institutes or design bureaux. In the face of the challenges by procurement innovations, design, as a driving force to enhance construction competitiveness, is yet to be realized. 
Even for the construction part of a project, where CICCs possess much strength, the interviewees reflected that:

Some of our pride project managers, having successfully managed billion dollars projects in China, feel helpless overseas even in front of small projects worth only a few millions.

An interviewee supplemented that:

International project managers are doing stakeholder management, while our managers are still focusing on site management only. Some of them still used the old practices. Managing BOT projects using traditional DBB experience is doomed to failure.

In diagnosing the problems, the interviewees ascribed them to institutional difference.

Why do CICCs possess competitive advantages in Africa? Because there is barely any institutional constraint in Africa. Our practices, good or bad, are "the practices”. But in European or North American markets, we have to get used to others' game rules including international technical standards, norms, and laws. Procurement innovations, which require integration, further add to the complexity of the business environment.

In acclimatizing, a “wait-and-see” culture towards procurement innovation has been observed in CICCs. They wait for other companies, in particular those SOEs, to be "the first person to eat a crab". This is further exacerbated by the booming indigenous construction market, resulting in some CICCs preferring the Chinese comfort zone. Nevertheless other CICCs exist pioneering procurement innovation as a proactive competitive strategy in the overseas market. Interviewees reflected that

CICCs are learning as they go, although there are a lot of unsuccessful cases. We should do knowledge management. Companies paid the tuition fee (for unsuccessful 
cases), while the experiences or lessons are still staying with individuals.

An interviewee suggested:

If you have strong design capability, you can undertake D\&B projects. If you have strong financial capability, you can conduct BOT projects. If you have unique sources for specialty machinery, you can do related EPC projects. Basically, procurement innovation provides CICCs with many opportunities to sharpen their competitive edge in the international construction market.

Rather than just by aligning competence within their own organizations CICCs have started to collaborate with other international companies in many ways. For example, some CICCs adopted a strategy, called “co-opetition” by researchers (e.g. Brandenburger and Nalebuff, 1996; Flanagan, 2009; Eriksson, 2008). This involves collaboration with other companies in one market segment, a region, or even a particular project, while compete fiercely against them in other segments, regions, or projects. In so doing, CICCs and their international counterparts can complement each other's strengths, enabling more projects to materialize than would be the case using traditional modes.

\section{Conclusions}

Chinese international construction companies (CICCs) are gradually adopting procurement innovation as a competitive strategy. They benefit from the huge domestic market which provides business buffer and also materials and labors for international ventures. Uneven strengths and weaknesses exist with respect to the integration of technical expertise, professional services, management skills, and finance. Such integration is of imperative importance to procurement innovation and the current CICCs uneven strengths and weaknesses must be ironed out. 
Although it is clear that procurement innovation will enhance CICC competitive advantage in the long term, there is a learning curve to be followed first. This study has shown the existence of a "wait-and-see" attitude. Actually, unlike the traditional win-lose competition, competing through procurement innovation makes more projects possible and CICCs, making use of their particular strengths, can be encouraged to deliver more international projects and more value to international society. This technical note can be read in conjunction with others exploring company competitive strategies by probing key trends in the international construction market. Future research is suggested in the field of procurement innovation to better appreciate the perspectives of all international companies and not just those of CICCs.

\section{References}

Brandenburger, A. and Nalebuff, B. (1996), Co-opetition: a revolution mindset that combines competition and cooperation, Harvard Business Press, Cambridge, MA.

CBI/QinetiQ Innovation (2006), Innovation and public procurement: A new approach to stimulating innovation, Innovation Brief, CBI, Oct, 2006.

Egan, J. (1998), Rethinking Construction (the Egan Report), Department of the Environment, Transport and the Regions, HMSO.

ENR (2008), The Top 225 International Contractors, Engineering News-Record, 261(5), 8/18/2008.

ENR (2010), The Top 225 International Contractors, Engineering News-Record, 265(6), 8/30/2010. 
Eriksson, P.E. (2008), Procurement Effects on Coopetition in Client-Contractor Relationships, Journal of Construction Engineering and Management, 134(2), 103111.

Flanagan, R. (2009), Market Entry and Growth Strategies in an International Market, Keynote Speech, Polish Contractors Federation, August, 2009.

Franks, J. and Harlow, P.A. (1990), Building Procurement Systems, CIOB: UK.

Godfrey, K. A. (1996), Partnering in Design and Construction, McGraw-Hill.

Hughes, W., Hillebrandt, P., Greenwood, D., and Kwawu, W. (2006), Procurement in the Construction Industry: The Impact and Cost of Alternative Market and Supply Processes, Taylor and Francis: New York.

Kumaraswamy, MM and Dissanayaka, SM (1998) Linking procurement systems to project priorities, Building Research and Information, 26 (4), 223-238.

Lu, W.S., Li, H., Shen, L.Y. and Huang, T. (2009), A SWOT analysis of Chinese construction companies in the global market, Journal of Management in Engineering, ASCE, 25(4), 166-176.

MacDonald, M. (2002), Review of Large Public Procurement in the UK, HM Treasury, London,

Masterman, J.W.E. (1992), An Introduction to Building Procurement Systems, E\&FN Spon.

McDermott, P., Melaine, Y. and Sheath, D. (1994), Construction Procurement Systems: What Choice for the Third World, 203-211.

Patrascu, A. (1988), Construction Cost Engineering Handbook. New York: M.Dekker. Porter, M.E. (1990), The Competitive Advantage of Nations, Free Press, New 
York/Collier Macmillan, London.

Raisbeck, P., Duffield, C. and Xu, M. (2010), Comparative performance of PPPs and traditional procurement in Australia, Construction Management and Economics, 28 (4), $345-359$.

Rogers, E. (1995), Diffusion of Innovations (4th ed.), New York: The Free Press.

Rowlinson S. and P. McDermott (1999), Procurement systems A Guide to Best Practice in Construction, London: E \& FN Spon.

Turner, A. (1990), Building Procurement, Macmillan Surveying Series, London.

Walker, D. H. T. and Hampson, K. D. (2003), Procurement Strategies: A Relationship Based Approach, Oxford: Blackwell Publishing.

Walker, D.H.T. and Rowlinson, S.M. (2008), Procurement Systems: a Cross-Industry Project Management Perspective, Taylor and Francis: New York.

Winch, G. (2000), Institutional reform in British construction: partnering and private finance, Building Research and Information, 28, 141-155. 